\title{
CONSIDERAÇÕES INICIAIS \\ A RESPEITO DE TEXTO \\ E IMAGEM NO LIVRO DE \\ LITERATURA INFANTIL
}

Marta Morais da Costa*

"7 de que serve um livro sem figuras nem diálogos?", pergunta-se Alice em sua primeira interrogação a respeito do mundo em Aventuras de Alice no

País das Maravilhas ${ }^{1}$. O livro lido por sua irmã foi uma das causas da sonolência que a fez precipitar-se no mundo da fantasia.

É preciso considerar que o livro infantil ocupa lugares diferentes em nossa cultura: primeiramente enquanto objeto tradicional, serve à decodificação do verbal e do visual, ao desenvolvimento do imaginário e pertence à história da cultura; num segundo enfoque, o livro infantil pode ser encarado enquanto passatempo, meio de comunicação, objeto da cultura de consumo e instrumento didático-pedagógico; e,

* Universidade Federal do Paraná e Pontifícia Universidade Católica do Paraná.

1 CARroll, Lewis. Aventuras de Alice no Pais das Maravilhas. Através do espelho e o que Alice encontrou lá. Trad. e org. Sebastião Uchoa Leite. $3^{4}$ ed. São Paulo: Summus, 1980.

2 SANTAELLA, Maria Lúcia \& NÖTH, Winfried. Imagem, cognição semiótica e mídia. São Paulo: Iluminuras, 1998. p.18-19. 
COSTA, M. M. Consideraçōes iniciais a respeito de texto...

por fim, enquanto veículo de comunicação, a ilustração funciona como chamariz de leitura e de consumo.

Refletindo sobre a questão de Alice e sobre os significados do livro na perspectiva cultural, podemos estabelecer dois caminhos de reflexão. O primeiro salienta a atração que exercem sobre o leitor as figuras de um livro, ajudando por vezes na compreensão do escrito, evitando o desinteresse e a sonolência. $O$ segundo intensifica a importância do imaginário que, sem o alimento de figuras e palavras, vê dificultada a criação de histórias próprias, a partir do impulso do livro, que se torna, então, perdido para a atenção do leitor. De que servem figuras e texto senão para alimentar, num moto perpétuo, mais imagens e mais histórias?

Na perspectiva infantil, um livro sem figuras não tem serventia. Já para os adultos, um livro com figuras permite redescobrir os sentidos da obra. Seja na produção para crianças, seja em livros para adultos, não há como negar que a união entre ilustração e texto tem produzido obras de rara beleza e de múltiplos sentidos.

Para Maria Lúcia Santaella é possível distinguir quatro tipos de escrituras: maiúsculo;

- as que brotam do gesto e da mímica, de que o teatro é um exemplo

- as vinculadas ao olhar (pictogramas e ideogramas), em que podemos localizar a ilustração;

- as fonéticas (hieroglifos);

- as alfabéticas (combinação arbitrária e finita de sons), em que se posiciona a linguagem verbal.

Esses tipos puros admitem, como se pode perceber numa primeira leitura, uma interrelação, multiplicando-se numa combinatória limitada mas enriquecida de escrituras.

Luria, em 1973, ao analisar o cérebro humano e os lugares em que se formam as imagens, definiu que o hemisfério esquerdo do cérebro tende a ser o dominante na fala, nas atividades de linguagem e no pensamento lógico. Seu funcionamento é analítico e seqüenciàl. Já o hemisfério direito dá conta do não-verbal, das habilidades espaciais, visuais e musicais. Funciona holística e sinteticamente. Mas a divisão não é universal pois os dois tipos podem acontecer no mesmo hemisfério. $O$ verbal não é exclusivamente o lingüístico e não é congênito, porque aumenta e se desenvolve. Também não é irreversível pois, em caso de lesão, um hemisfério pode substituir o outro.

No aspecto neurológico, portanto, já vemos desenhar-se uma predisposição para um trabalho conjugado de formação de imagens visuais e verbais simultaneamente no cérebro humano. Essa qualidade é fundamental para que se realize a leitura de um livro ilustrado.

O poder de atração que as imagens gravadas nas páginas de um livro representa para os leitores é que interessa a este estudo investigar, mesmo porque as histórias com figuras, também chamadas ilustradas, compõem hoje um binômio 
COSTA, M. M. Considerações iniciais a respeito de texto...

inseparável e solicitado tanto pelos adultos ao oferecer a leitura para as crianças quanto pelos leitores mirins, condicionados a esse tipo de publicação dúplice.

Sabemos que a palavra escrita constitui por si só um desenho a cujos traços corresponde, por uma relação arbitrária, um som. À cadeia sonora formada pela associação de sons chamou-se palavra, cujo significado arbitrário herdamos. A escrita e sua leitura não estão, portanto, dissociadas do grafismo. E sobre ele edificamos continuadamente os sentidos dos textos.

Mas para quem não domina o alfabeto, outras imagens permitem manter o contato com a representação do mundo e com a produção de sentidos: as imagens visuais resultantes da representação, figurativa ou não, do mundo e dos pensamentos. Seria, entretanto, minimizar o poder da imagem tomá-la apenas no sentido informativo e complementar de lacunas culturais. A linguagem visual, tal como a verbal, possui um sistema sígnico próprio que a constitui organicamente, capaz de servir para a transmissão da herança cultural e da criação artística, além de sua função representativa e informativa.

Para pensar aqui a natureza e a significação da imagem se faz necessário delimitar-lhe que espécie será avaliada: não se tratará aqui de quadrinhos, da publicidade, do cinema, nem do livro de figuras ou o do livro sem texto, mas a literatura infantil, não textos inventivos em imagens mas com imagens.

Há, porém, na relação texto-imagem limites permanentes: nem a palavra consegue substituir a imagem, por mais que tente descrevê-la, nem a imagem é capaz de reproduzir a sonoridade da palavra e a multiplicidade de sentidos que ela é capaz de evocar. Mas, respeitando as respectivas idiossincrasias, texto e imagem podem somar-se e ampliar os sentidos das mensagens.

Nessa direção caminha a presente reflexão. Em especial, o questionamento sobre qualidades e efeitos que nascem da aliança texto\&imagem na literatura infantil, na qual desaguam diferentes estilos e técnicas.

Uma primeira função dessa multiplicidade é a de introduzir o leitor no mundo simbólico e cultural de maneira intensa, por meio de objetos circulantes em seu cotidiano. A família e a escola têm assegurado leitores cativos da produção editorial destinada à criança. Principalmente ao insistir no livro de "figuras", condição sine qua non estabelecida por adultos para qualificar o livro infantil. Se não tiver figuras, dizem, é livro adulto, desinteressante ou para adolescentes. A partir desse pressuposto, adultos acentuam, priorizam, intensificam a associação palavra\& imagem, acabando por viciar o leitor, criando uma dependência tal que muitas vezes ele se sente abandonado e indefeso diante de um texto exclusivamente verbal. É mais comum do que se imagina deparar-se com jovens e adultos que condicionam sua leitura literária à espessura e à existência de ilustrações nos livros.

Em segundo lugar, cabe recuperar um pouco da história dessa união. $O$ livro que une imagens e texto não é uma invenção de nosso século: de que tempos e formas nós o herdamos? 
A aliança entre o verbal e o visual na história do livro tem, segundo Ângela Lago ${ }^{3}$ três grandes momentos: o manuscrito medieval, as obras para crianças do final do século XIX e início do século XX e os livros infantis contemporâneos.

Ao longo da Idade Média "a qualidade plástica dos laboriosos manuscritos medievais" não apenas representava a realidade e o imaginário de seu tempo mas já anunciava recursos gráficos que influenciariam ilustradores contemporâneos, bem como se aproximavam em sua forma de narrar ao modo como a criança narrativiza seu cotidiano.

Quem já teve a felicidade de ver/ler qualquer manuscrito desse período deve ter sentido o fascínio que as imagens nele inscritas despertam. O cromatismo, o grafismo, a composição gráfica, a religiosidade, os costumes, a cultura dos povos que nele se materializam tornam concreta a história daquela época, estabelecem o elo com o presente, realçam a arte de esquecidos, porque anônimos, artesãos.

Em 1845, Rodolphe Topffer, precursor das tiras ilustradas atuais, defendia a ilustração com as seguintes palavras:

Há duas maneiras de escrever histórias: uma em capítulos, linhas e palavras, e a isso chamamos literatura; ou alternativamente, por uma sucessão de ilustrações, e a isso chamamos história ilustrada.(..) A história ilustrada à qual a crítica de arte não dá atenção e que raramente preocupa os letrados sempre exerceu grande atração. Mais, na verdade, que a própria literatura, pois além do fato de que há mais gente capaz de ver que de ler, agrada às crianças e às massas, parcelas de um público que seria especialmente desejável promover. Com a dupla vantagem de apresentar concisão e clareza, a história ilustrada, em condiçōes de igualdade, acabará por suplantar a outra, por dirigir-se com maior agilidade a um maior número de mentes; e também porque, em qualquer contexto, aquele que emprega um método tão direto leva vantagem sobre os que falam por capítulos. ${ }^{5}$

O texto permanece atual quando discorre sobre o poder da imagem. Mas o tempo se encarregou de desmentir o prognóstico assustador a respeito do desaparecimento do verbal. Nem a imagem perdeu seu poder de agradar e ensinar

3 LAGO, Ângela \& ALBERGARIA, Lino. "Concepção do Livro de Imagem". Texto apresentado no Ill Congresso da Fundação Nacional do Livro Infantil e Juvenil. Mimeo.

4 LAGO, op. cit. p.6.

5 Apud LAGO, Ângela, op. cit. p.4. 
COSTA, M. M. Consideraçōes iniciais a respeito de texto...

nem o texto desapareceu sob o império da "história ilustrada". Prevaleceu a convivência entre eles.

No período entresséculos domina a ilustração a arte de Gustave Doré, cujo realismo do desenho, colado à referencialidade dos objetos representados, cria uma atmosfera sugestiva que instiga o imaginário. Sua ilustração para as histórias de Charles Perrault, o autor dos memoráveis Contos da Mamãe Gansa - que denominamos carinhosamente de contos de fada - demonstra o domínio do artista sobre o jogo de luz e sombra, o detalhismo e a propriedade com que apreendeu o universo do imaginário humano que os contos exploram.

Entre os grandes nomes dessa arte, Ângela Lago faz referência à obra de Edmund Dulac que, influenciado pela pintura japonesa, pelos pré-rafaelitas e por Gustav Klimt, recriou os climas mágicos dos contos das Mil e Uma Noites.

No Brasil, datam de 1915 as ilustrações dos irmãos Weiszflog para $O$ Patinho Feio, de Andersen, primeiro livro infantil ilustrado em nosso país. Até então os livros eram impressos na França e chegavam ao Brasil com as imagens feitas na Europa. Mas o grande momento inicial da ilustração de textos infantis acontece em 1920 com a publicação de A Menina do Narizinho Arrebitado, de Monteiro Lobato, ilustrado por Voltolino, "o mais importante caricaturista de São Paulo do início do século". Esse trabalho não facilita ou infantiliza o traço por estar dentro de um livro para crianças: ao contrário, respeita o olhar infantil, desafiando-o a ler as filigranas estéticas do grafismo de Voltolino.

Outra obra que marca indelevelmente a história da ilustração no Brasil é Flicts, de Ziraldo (1969). Antecipando o início da moderna literatura infantil brasileira que foi a década de 70 . Flicts constitui até hoje um desafio ao olhar conservador da escola - que demonstra clara preferência pela ilustração figurativa ao contar não apenas a história de uma cor, mas ao utilizar as formas geométricas como personagens, narração e diálogo.

Hoje, a literatura infantil pode contar com o trabalho constante e já sedimentado num estilo próprio de ilustradores como Ângela Lago, Eva Furnari, Ricardo Azevedo, Helena Alexandrino, Alcy, Regina Yolanda, Ana Raquel, Luís Camargo, Ciça Fittipaldi e tantos outros.

Para Maria Alice de Oliveira Faria ${ }^{7}$ um balanço geral da produção brasileira aponta " três visões de mundo diferentes: a realista, a representação da fantasia e o humor." Esta classificação se pauta pela predominância de estilos, embora a autora reconheça mais um, o experimentalismo, ainda minoritário diante dos outros três.

6 CAMARGO, Luís. Ilustração do Livro Infantil. Belo Horizonte: Lê, 1995.

7 FARIA, Maria Alice de Oliveira. A ilustração no livro infantil contemporâneo. Proleitura, Assis, UNESP, ano I, $n^{\circ}$ ). p. 4, jun. 1992. 
Numa posição um pouco mais descritiva, em A llustração do Livro Infantil, Luís Camargo distingue de outra maneira os diferentes estilos: descrição (a imagem visualiza concretamente metáforas e sentidos do texto), geometrização, estilização (apresentando uma simplificação de formas), rabiscação (o registro de um movimento, risco, gesto, rabisco), abstração (ênfase na geometrização ou rabiscação); humanização (freqüente em bichos e plantas); quadrinização (utilização de procedimentos visuais de histórias em quadrinhos: balōes, quadros, onomatopéias, recursos gráficos).

O que se pode afirmar, sem sombra de dúvida, é que a variedade e a técnica cada vez mais apurada têm sido uma das conquistas dos ilustradores brasileiros. Hoje, podemos contar com uma produção que ombreia com a dos países de Primeiro Mundo, como se pôde observar em algumas exposições itinerantes de ilustradores do mundo todo que foram apresentadas ao público curitibano e na produção bibliográfica exposta nas bienais do livro de São Paulo e Rio de Janeiro.

Num livro ilustrado, as indagações a respeito das funções que a visualidade preenche enquanto arte e enquanto comunicação com o leitor constituem um aspecto relevante a ser estudado. Luís Camargo distingue sete funções principais: a de pontuação (coloca em destaque e marca o início e o fim de parágrafos, capítulos ou textos, é uma espécie de vinheta), a descritiva (identifica animais, plantas, objetos; extremamente frequiente na literatura infantil), a narrativa (como se pode observar nos livros sem texto), a simbólica (metafórica, representando sempre uma idéia universal), a expressivalética (figuras retratam sentimentos, emoções e valores do ilustrador), a estética (chama a atenção para a maneira como foi realizada), a lídica (a ilustração vira jogo e o livro torna-se interativo) e a metalingiuística (a linguagem que fala sobre ela mesma) ${ }^{8}$.

Essas funções não são excludentes, mas integram-se no conjunto de imagens de um mesmo livro, oferecendo ao ilustrador e ao leitor a oportunidade de vivenciar, por meio do olhar dirigido à realidade, o imaginário, a reflexão, o prazer e o conhecimento. As funções se definem em relação ao texto e não implicam valoração de ordem artística ou estética. Foram assim classificadas para que se compreenda melhor como a imagem pode conviver com a literatura, seja para ampliar seus sentidos seja para constituir-se, enquanto dupla linguagem, uma outra leitura que merece, ela também, ser interpretada pelo leitor. Tal como o verbal, a ilustração propõe ao leitor desde cedo um exercício de leitura num código com leis e sintaxe próprias e desafiadoras.

Embora tenhamos tratado na maior parte do texto da literatura dirigida às crianças, não se pode esquecer que, embora rara, a ilustração tem sido companheira do texto verbal em obras para adultos, de que guardamos alguns exemplos valiosos: as revistas simbolistas da passagem do século XIX ao século XX no Paraná, a obra 
de Guimarães Rosa ilustrada por Poty Lazarotto, $O \mathrm{Mez}$ da Grippe, de Valêncio Xavier e os poemas visuais criados a partir do Concretismo e do Poema Processo, a dupla linguagem da criação de Amaldo Antunes, além de outros casamentos felizes dessa duas artes, como Macunaíma, de Mário de Andrade, ilustrado por Carybé.

Não se pode deixar de enfatizar que a coexistência de "diálogos" e "figuras" no mesmo volume não se destina especificamente a manter interessado o leitor principiante ou menos competente para abstraçōes. Trata-se de uma arte combinatória de nuances múltiplas que permite o trânsito entre linguagens, tão comum em nosso cotidiano e, mais do que isso, exige duplo esforço do leitor, capacitando-o a desempenhos de leitura cada vez mais completos e complexos. Ler a letra e a imagem integradamente é um desafio que requer habilidades complexas, de vez que toda imagem, por mais literal que pareça, envolve uma distorção ideológica em relação ao real e demonstra um sistema de representação que resulta de sínteses históricas, seja da linguagem visual, seja dos sentidos que o ilustrador foi construindo ao longo de sua história pessoal de leitura e que projeta na ilustração que apresenta ao leitor.

Segundo Gibson", à percepção do mundo espacial (estético) soma-se à percepção dos objetos, que serão convertidos em sinais e símbolos escritos, num exercício pragmático. Há, portanto, uma combinação do mundo visual (estar/agir, fora do observador) e do campo visual (cenas enquadradas pelo observador). $\mathrm{E}$ nessa simbolização em forma de linguagem, há uma simbiose entre natureza e convenção, que converte o texto pictórico em um discurso simultaneamente individual e histórico.

Maria Lúcia Santaella divide triadicamente as imagens: näo-representativas, que procuram reproduzir a aparência da imagem em si, como a representação de figuras mitológicas, seres imaginários, a Justiça, a árvore genealógica; figurativas, que expressam as relações da imagem com o referente e representativas ou simbólicas, como, por exemplo, as leis que determinam o mundo e como devem ser interpretadas.

Uma análise ainda incipiente da produção bibliográfica destinada a crianças detecta a intensa ocorrência de ilustrações figurativas, como a atestar a relação primária estabelecida entre o ilustrador, o conceito de leitor modelo ${ }^{10} \mathrm{e}$ a concepção realista e causalista do papel da ilustração.

Escolas e editoras exercem papel preponderante na formação de um, denominemos assim, gosto pela imagem figurativa, de contornos bastante definidos,

9 Apud SANTAELLA, Lucia \& NÖTH, Winfried. Imagem: cognição, semiótica, mídia. São Paulo: Iluminuras, 1998.

10 ECO, Umberto. Seis passeios pelo bosque da ficção. São Paulo: Companhia das Letras, 1994. 
COSTA, M. M. Consideraçōes iniciais a respeito de texto...

de cores realistas e fortes, aproximados estreitamente ao fotográfico. Nos últimos anos, a caricatura, essa deformação em busca de maior precisão realista, também tem ocupado as páginas coloridas da literatura infantil, acompanhando a intensificação das qualidades de humor e prazer epidérmico, defendidas como princípios de um bom livro infantil por educadores e editores.

Em termos educativos, sabemos o quanto condiciona o leitor infantil uma mesma forma de representação pictórica do mundo. A recusa - muitas o repúdio de imagens abstratas, geométricas ou surrealistas da parte de professores e público infantil demonstra que não se vive impunemente na companhia de patos, ursos e plantas realisticamente reproduzidas.

Em termos de uma análise para melhor compreensão da linguagem visual tal como se apresenta na produção literária para crianças, convém lembrar o que Philadelpho Menezes ${ }^{11}$ realça como perspectivas para a observação do fenômeno. São três os ângulos pelos quais se pode questionar as relações entre o visual e o verbal:

- a figuratividade, que leva em consideração o signo frente ao objeto;

- a sintaxe definidora, para o estudo das relações com os outros signos;

- o leitor, em quem se pode observar a construção mental do figurativo e da sintaxe.

O uso mais freqüente que a escola faz do signo visual, configurado na ilustração, resume-se freqüentemente à figuratividade e à formação do leitor. Trocando em miúdos, os educadores têm demonstrado em relação ao livro ilustrado um tratamento que vai da admiração a-crítica pelas soluções criativas de algumas imagens a uma busca da comparação um a um entre a imagem e a realidade que ela representa. É muito comum a utilização das páginas ilustradas para que seja chamada a atenção do leitor mirim para a qualidade mimética da representação do real por meio de perguntas como: "o que é isto?", "como está vestida fulana?", "que caminho é este ?" e assim por diante. Pouco se detém o educador na relação sintática entre as imagens e muito menos na sintaxe palavra-imagem visual, é como se os livros estivessem formados apenas por gravuras independentes, com a função exclusiva de figurar o real.

Com apoio na poesia contemporânea, Menezes chega à conclusão de que há pelo menos três modelos de relação entre o verbal e o visual: "a visualidade como estrutura do verbal, a visualidade como sintaxe das formas plásticas puras e a visualidade semantizada da montagem intersígnica." Para ele, há um "traçado evolutivo" nesses estágios de relacionamento.

11 MENEZES, Philadelpho. Poética e visualidade: uma trajetória da poesia brasileira contemporânea. Campinas (SP): Unicamp, 1991.

12 Idem, p, 175-176. 
COSTA, M. M: Considerações iniciais a respeito de texto...

Aplicando-se esses conceitos à ilustração dos textos infantis, pode-se perceber como eles coexistem na produção contemporânea e como a visualidade semantizada representa um momento qualitativo superior da relação texto e imagem de vez que integra e intensifica os sentidos dos textos visual e verbal. Verificamos em textos exemplares como Eu e minha luneta, de Cláudio ou O homem do sótão, de Ricardo Azevedo, que a complementação do sentido das palavras só é possível quando acrescentamos a elas as imagens, que não apenas referendam o que está escrito, mas ainda ampliam os valores e os elementos narrativos.

Ainda podemos recorrer a Genette e a suas categorias de relações intertextuais para estabelecer para as ilustrações a mesma classificação e valores que ele criou para o texto verbal: a intertextualidade, ${ }_{\gamma_{3}}$ a hipertextualidade, a metatextualidade, a paratextualidade $\mathrm{e}$ a arquitextualidade ${ }^{3}$. Os mesmos fenômenos encontramos na ilustração, visualidade a remeter continuadamente a outros textos. Exemplos bem realizados dessa citação encontramos em $O$ menino mais bonito do mundo, em que Ziraldo atualiza $O$ nascimento de Vênus, de Boticcelli e em De morte, em que Ângela Lago recupera e re-contextualiza as imagens de Albrech Dürer, dando ao conto uma contraface das imagens aterrorizantes provindas de leituras bíblicas apocalípticas, que o texto verbal, de tons picarescos, atenua.

Exemplo especial de intertextualidade é registrado pela coleção "Arte para criança" em que os textos visuais de pintores de expressão como Volpi e Tomie Otake, entre outros, dialogam com a escrita de narradores de alta qualidade poética, como Ana Maria Machado e Lygia Bojunga Nunes ${ }^{1.4}$.

Quando a escola trata a ilustração como complemento da escrita, entende a imagem apenas como uma maneira de explicitar o que as palavras dizem. Com isso, está seguramente minimizando o potencial de sentido que a imagem visual traz ao livro, enquanto uma linguagem artística, a ilustração pode e deve buscar nos elementos de sua composição construir o efeito estético a ser provocado no leitor. Bardin afirma que, "no caso de disposição lado a lado de texto e imagem, não se trata de uma mera adição de duas mensagens informativas diferentes. Uma nova interpretação holística da mensagem total pode ser derivada dessa disposição."

Mais evidente fica essa relação integradora e totalizante quando encontramos obras produzidas por um escritor/ilustrador único. Ricardo Azevedo, Ângela Lago, Eva Furnari e Ziraldo são alguns exemplos da simbiose de duas linguagens a produzir um resultado que não consegue separar imagens lingüísticas e visuais. Por meio deles tomamos consciência da efetiva e ampla possibilidade comunicacional de um livro ilustrado.

13 GENETTE, Gérard. Palimpsestes. Paris: Seuil, 1982.

14 Um dos exemplos é MACHADO, Ana Maria. Era uma vez três... 2 ed. São Paulo: Berlenda \& Vertecchia, 1995.

15 Apud SANTAELLA, op.cit. p.55. 
Ângela Lago explora ao máximo essa relação em $A$ novela da panela ${ }^{16} \mathrm{em}$ que, retomando alguns recursos de cartas enigmáticas dos almanaques antigos, realiza uma referência substitutiva, em que "imagens em forma de enigmas substituem palavras no meio do texto escrito" . Ao mesmo tempo em que se reporta ao aspecto lúdico da leitura, abre espaço para a reflexão a respeito da intensificada visualidade da cultura contemporânea, em que a síntese textual com a decorrente diminuição do tempo de leitura de mensagens traz ao espaço do livro procedimentos de leitura frequientes na realidade extra-livro.

Convém ressaltar que a tendência em transformar o objeto livro numa espécie de réplica da televisão, pela exigência absoluta de que as palavras não se bastem, obrigando à complementação da imagem visual, tem sido uma das causas das dificuldades em se conquistar o adolescente para a leitura de textos minimamente ilustrados ou sem ilustração alguma. O que era um chamariz para o leitor infantil transformou-se em vício no adolescente.

Seja por motivos culturais ou de tecnologia avançada - que permite edições e recursos cada vez mais sofisticados - a sobreposição da imagem à palavra ocasiona a poluição do olhar, cada vez mais afetado e acostumado pela redundância e continuidade a imagens reprodutivas, sem orientação e/ou formação adequada para a leitura de imagens complexas. Verifica-se, também no âmbito das imagens visuais, a padronização dos modelos e a criação de horizontes de expectativa ${ }_{18}$ cada vez mais limitados. $O$ que não deixa de ser um paradoxo se considerarmos a inflação de estímulos visuais da sociedade de consumo moderna.

\section{RESUMO}

A ilustração do livro infantil apresenta vários desafios à teoria semiótica e às teorias da leitura porque implica simultaneamente a leitura de signos visuais e verbais, imbricados de forma a exigir a interpretação holística. A presença da ilustração nos livros exige, também, dos educadores um tratamento menos ocasional e mais especializado para evitar que a linguagem visual seja lida apenas como complemento do verbal. Existe ainda um forte componente consumista e reprodutor na exigência de imagens figurativas, em detrimento das simbólicas, abstratas ou geométricas.

Palavras-chave: literatura infantil, texto e imagem.

16 LAGO, Ângela. A novela da panela: um drama quase completo. São Paulo: Moderna, 1998. 17 SANTAELLA, op. cit. p. 56.

18 ISER, Wolfgang. El proceso de la lectura. In: WARNING, Rainer. (org.). Estética de la recepción. Madrid: Gredos, 1989. 
COSTA, M. M. Considerações iniciais a respeito de texto...

\section{RÉSUMÉ}

L'illustration du livre pour les enfants présente plusieurs défis à la téorie sémiotique et aux téories sur la lécture parce qu'elle crie la nécessité d'une lecture simultanée des signes visuels et verbaux, liés étroitement d'une façon éxigeant une interprétation holistique. La présence de l'illustration des livres éxige, aussi, des éducateurs un traitment moin ocasionnnel et plus spécialisé a fin d'éviter que le langage visuel soit lit uniquement comme un complément du verbal. Il éxiste, néamoins, un très fort élément de consume et de réproduction en l'éxigence des images figuratives, en détriment des symboliques, abstraites ou géometriques.

Mots-clés: littérature infantile, texte et image.

\section{REFERÊNCIAS}

CAMARGO, Luís. Ilustração do Livro Infantil. Belo Horizonte: Lê, 1995.

CARROLL, Lewis. Aventuras de Alice no País das Maravilhas. Através do espello e o que Alice encontrou lá. Trad. e org. Sebastião Uchoa Leite. 3* ed. São Paulo: Summus, 1980.

ECO, Umberto. Seis passeios pelo bosque da ficçāo. São Paulo: Companhia das Letras, 1994.

FARIA, Maria Alice de Oliveira. A ilustração no livro infantil contemporâneo. Proleitura, Assis, UNESP, ano $I, n^{\circ}$ ). p. 4, jun. 1992.

GENETTE, Gérard. Palimpsestes. Paris: Seuil, 1982.

ISER, Wolfgang. El proceso de la lectura. In : WARNING, Rainer (org.). Estética de la recepción. Madrid: Gredos, 1989.

LAGO, Ângela. De morte: conto meio pagão do folclore cristão. Belo Horizonte: RHJ, 1992.

. A novela da panela: um drama quase completo. São Paulo: Moderna, 1998.

LAGO, Ângela \& ALBERGARIA, Lino. "Concepção do Livro de Imagem". Texto apresentado no III Congresso da Fundação Nacional do Livro Infantil e Juvenil. Mimeo.

MACHADO, Ana Maria. Era uma vez três... 2 ed. São Paulo: Berlenda \& Vertecechia, 1995.

MARTINS, Cláudio. Eu e minha luneta. Belo Horizonte: Formato, 1992.

MENEZES, Philadelpho. Poética e visualidade: uma trajetória da poesia brasileira contemporânea. Campinas (SP): Unicamp, 1991.

MITCHELL, W.J.T. Iconology: image, text, ideology. Chicago (USA): University Press, 1986. Revista USP,p.38)

SANTAELLA, Maria Lúcia \& NÖTH, Winfried. Imagem, cognição semiótica e mídia. São Paulo: Iluminuras, 1998.

ZIRALDO. O menino mais bonito do mundo. Ilustr. Sami Mattar, Apoena Medina e Ziraldo. São Paulo: Ática, 1981. 